\title{
Personal, semantic and communicational aspects of helping among adolescents
}

\author{
Maria M. Nakonechna (1D $1 \cdot A, B, E$, Eugene Stepura (1D ${ }^{2 \cdot C, D}$, Mykola Papucha $\mathbb{I D}^{1,2 \cdot A}$, \\ Vladimir Koshel $\mathbb{1}^{3 \cdot D}$, Alexander Segal $\mathbb{1}^{4 \cdot E}$, Anna Fedorova $\mathbb{1}^{3 \cdot F}$ \\ 1: Nizhyn Gogol State University, Nizhyn, Ukraine \\ 2: G. S. Kostiuk Institute of Psychology of the National Academy of Educational Sciences of Ukraine, Kiev, Ukraine \\ 3: Plekhanov Russian University of Economics, Moscow, Russia \\ 4: Lomonosov Moscow State University, Moscow, Russia
}

\section{BACKGROUND}

The main research question of the article is how the perception of help and the style of interpersonal relations are connected. In a broad sense, the question refers to the problem of constant and situational variables of prosocial activity. The main methodological framework is $\mathrm{Vy}$ gotsky's cultural-historical psychology, in particular, the mechanism of interiorization and the interaction of interpsychological and intrapsychological processes.

\section{PARTICIPANTS AND PROCEDURE}

Over 215 participants (students attending school and university, living in Ukraine, aged from 12 to 22 years) took part in our experiment, but because not all of them completed all the necessary forms correctly, only 193 participants' answers were further analyzed. Our two research techniques were Leary's Interpersonal Behavior Circle Personal Inventory and the semantic differential $(N=193)$.

\section{RESULTS}

Each disposition from Leary's questionnaire had at least one significant correlation with the way Ukrainian adolescents perceive help. The semantic aspects of perceiving help were investigated with the help of ranking the qualities of the semantic differential for the words "help the other".

\section{CONCLUSIONS}

The identified correlations contribute to the psychological analysis of the detailed characteristics of perceiving help concerning personal dispositions. Personal, communicational and semantic aspects of help are interconnected and their further research can bring rich insights.

\section{KEY WORDS}

help; prosocial activity; personality; communication, adolescence

Corresponding Author - Maria M. Nakonechna, Ph.D., Nizhyn Gogol State University, 2 Hrafska Str., 16600 Nizhyn, Ukraine, e-mail: maria.nakonechna@ndu.edu.ua

AUthors' contribution - A: Study design - B: Data collection - C: Statistical analysis - D: Data interpretation .

E: Manuscript preparation · F: Literature search · G: Funds collection

to Cite this ARTICLE - Nakonechna, M. M., Stepura, E., Papucha, M., Koshel, V., Segal, A., \& Fedorova, A. (2021).

Personal, semantic and communicational aspects of helping among adolescents. Current Issues in Personality

Psychology, 9(1), 37-45.

RECEIVED 08.06.2020 • REVIEWED 26.11.2020 • ACCEPTED 08.02.2021 · PUBLISHED 25.03.2021 


\section{BACKGROUND}

The psychological research of helping behavior started in the late 1960s. Nevertheless, it is still important to investigate some issues and questions connected with help, altruism, and prosocial actions. Prosocial activity, understood in the broadest sense, is the foundation of the stable society's development and well-being. If people act prosocially, it contributes to the good of others - whether it is another person, group of people or the whole of humanity. The level of prosocial activity can be an indicator of personal development and the quality of life in society, because the more people help each other and the less egoistic they are, the more possibilities of personal inner growth and development and social good arise. It is especially important for adolescents who form personal relations of friendship and love which are facilitated and supported by prosocial activity.

In the present work, the central question is: how is the perception of the help to others interconnected with the style of interpersonal relations? The answer to the question would give more in-depth scientific insight into the nature of helping activity.

To start with, a definition of the notion of help, the essence of the studied subject, is needed. Help is understood as the interaction with the other that is aimed at 1) the relief of suffering, and 2) the opening of potential capacities. Two aspects are essential here: 1) how one perceives help; 2) how one tends to act in situations where help is needed. Our present study corresponds to these psychological elements of the situation of help. However, at the same time, real-life situations of help are more complex and include a much greater variety of factors. This defines the weak spots of our research, but nevertheless, it shows its topicality and necessity. The aim is to study the perception of help and its interconnections with personal relational styles, which constitute the complex phenomenon of help. In order to study help in its complexity, one can start from perceiving help, because perception is an important part of helping as real-life activity.

The subject of our research is the interconnection of perceiving of help and personal relational styles. It should be underlined that the perception of help was studied, not help in real life situations, the latter being a more complex structure with more correlates and variables. There is a crucial difference between real-life help activity and perceiving help. While real-life help can include personal, situational, interactional, communicational and semantic aspects, the perception of help concentrates mainly on the semantic aspects. Nevertheless, perceiving help is interconnected with real-life helping, because on the basis of how people perceive help they choose to act towards it or not.
The theoretical basis for our research is $\mathrm{Vy}$ gotsky's cultural-historical psychology (Vygotsky, 1978). Nevertheless, it is essential to understand how help is described in different psychological theories. The self-determination theory (Deci \& Ryan, 1985) is one of them. In recent studies it has been found that autonomous motivation corresponds to more closeness than controlled motivation; research revealed that the more a person perceives the other as acting from autonomous motivation rather than from external causes, the more grateful and empathic this person will be (Weinstein et al., 2010; Reis et al., 2000; Tian et al., 2018).

Vygotsky's idea about the development of notions (Vygotsky, 1978) is crucial for our study, because the idea that help's perception is developing, that it is not stable and unchanging, is one of the fundamental ones. Meanwhile it is important to study the interconnections of perceiving help and interpersonal relations, which was the subject of our research.

Prosocial behavior correlates with positive psychology constructs, such as hope (Marques et al., 2011) and gratitude (Tsang, 2006). The connection of cognitive constructs with helping behavior was one of the critical interests of our present research.

Studying the personal aspects of help contributes to the micro level of analysis (Penner et al., 2005). The authors note that there is still a gap in our understanding of the interconnection of personal traits and prosocial responses (Penner et al., 2005, p. 375). Our present study aims to investigate the interconnection of perceiving help and personal traits, which can give a clue to the general picture of understanding the prosocial behavior psychologically. Vygotsky pointed out that the method should be appropriate to the research subject. So different levels of analysis are due to be interpreted when studying such a complex phenomenon as helping.

The role of expecting the moral emotions and in the broader perspective the moral sense of a person has been studied in the context of predicting different types of behavior, in particular, prosocial activity (Johnson \& Krettenauer, 2011; Ding et al., 2018). The interconnection of the leader's ethicality and the follower's intentions to act prosocially was found (Kacmar et al., 2013). The emphasis on moral emotions over moral cognitions (Van der Graaff et al., 2018) and on good praise (Wang et al., 2018) was proven to be significant in recent studies. It was shown that moral disengagement does not necessarily correlate with the absence of help (bystanding in bullying situations) (Doramajian \& Bukowski, 2015; Barlinska et al., 2018) or prosocial actions influenced by thirdparty anger (van Doorn et al., 2018). The positive effect of constructive news and peer discussions (Kleemans et al., 2017) and the negative impact of emotional dissonance (Park et al., 2019) on prosocial activity 
were investigated. The impact of being watched on prosocial acts was highlighted (Cañigueral \& Hamilton, 2019), along with the investigation of heroic deeds as prosocial ones (Kraft-Todd \& Rand, 2019). The connection between helping intentions and social distance in relations was studied (Zhang \& Zhao, 2017), which is essential for our study on the types of interactional dispositions.

The mediating function of cultural values in different types of prosocial behavior was found in a sample of Mexican-American early adolescents (Armenta et al., 2010). The cultural influence is essential for the personality in terms of cultural-historical psychology (Vygotsky, 1978), which is the methodological framework for our research. All these research findings add to the mosaic of our understanding of prosocial behavior. However, through the lens of Vygotsky's cultural-historical theory it is possible to interpret cultural differences as integrated in the social situation of development of a person (Vygotsky, 1978; Dafermos, 2018)

Prosocial activity can be understood within $\mathrm{Vy}-$ gotsky's cultural-historical theory as a complex interaction of agents aiming to facilitate growth or eliminate suffering. Being an interpsychological process, prosocial activity can lead to the personal development of intrapsychological processes through the mechanism of interiorization (Vygotsky, 1978).

The developmental aspects of help have been studied in various samples (Foulkes et al., 2018; Hepach \& Herrmann, 2019), e.g. in infants' (Hammond \& Brownell, 2018; Fonseca et al., 2018) and toddlers' prosocial behavior (Newton et al., 2016), in genetic aspects of prosocial behavior in a sample of twins (Knafo \& Plomin, 2006), in adolescents' prosocial activity (Pakaslahti et al., 2002; Freitas et al., 2019), and in mediating the influence of low social preference on aggression and depression among children (He et al., 2018). A longitudinal study was performed on children's emotions and cognitions influencing prosocial behavior (Malti et al., 2016). The inverse correlation of prosocial activity and autism disorders in adolescence was proven (Oerlemans et al., 2018).

The narratives of children and teenagers were studied in the context of reasoning different types of actions, e.g., help to the other (Recchia et al., 2015). Although our study used a different method, the general field of research is similar. The problem of research methods for investigating prosocial activity was systematically reviewed recently (Martí-Vilar et al., 2019).

Vygotsky's ideas about interfunctional psychological systems (Vygotsky, 1978) are very important to understand the psychological nature of help. According to Vygotsky's cultural-historical theory, helping induces the developing and changing interfunctional psychological systems, where various psychological functions are included, for instance the perception of help is connected to the style of interpersonal relations, as highlighted in our empirical study.

The problem of contemporary investigations in the field of prosocial behavior lies in the fragmentary nature of the research and its focus on particular matters. A fundamental analysis of the theory and methodology of prosocial behavior in psychology is needed.

Leary notes: "Behavior which is related overtly, consciously, ethically, or symbolically to another human being (real, collective, or imagined) is interpersonal" (Leary, 2004, p. 4). These ideas are close to Vygotsky's theory about interpsychological processes. According to Vygotsky, each psychological function appears on the scene twice: first as interpsychological, collective, and second as inner, intrapsychological. So the psyche is deeply interconnected with the relations with others, first of all the close family. The style of interpersonal relations, according to Leary, is the way a person usually behaves towards the others and lies on the continuum from autocratic to generous and caring interpersonal behavior strategies.

The research hypothesis is that the semantic aspects of perceiving help are interconnected with the styles of personal relations.

The research questions were as follows:

- Which aspects of perceiving help are connected with interpersonal prosocial relations, such as cooperative and responsible?

- How are the peculiarities of perceiving help connected with the styles of interpersonal relations, particularly non-prosocial ones, such as autocratic and narcissistic?

- What is the interfunctional psychological system (Vygotsky) that unites the perception of help and the style of interpersonal relations and facilitates further development?

These and other questions were addressed in the empirical study.

\section{PARTICIPANTS AND PROCEDURE}

\section{PARTICIPANTS}

Over 215 participants (students attending school and university, living in Ukraine, aged from 12 to 22 years) took part in our experiment, but because not all of them completed all the necessary forms correctly, only 193 participants' answers were further analyzed. The experiment was anonymous, and the respondents did not specify their age or gender (their age was determined by analyzing the journals where the dates of birth are indicated; due to the fact that they were not all present the exact gender proportion is not known, but the approximate percentages are $46 \%$ male, $54 \% \mathrm{fe}-$ male). The participants studied at the $8^{\text {th }}$ to $11^{\text {th }}$ classes of school and the $1^{\text {st }}$ to $3^{\text {rd }}$ years of university. 


\section{MEASURES}

Leary's Interpersonal Behavior Circle Personal Inventory. The first group of variables is managerial - autocratic (I), competitive - narcissistic (II), aggressive - sadistic (III), rebellious - distrustful (IV), self-effacing - masochistic (V), docile - dependent (VI), cooperative - over-conventional (VII) and responsible - hyper-normal (VIII) personal dispositions. They were measured by Leary's Interpersonal Behavior

\section{Table 1}

Means and standard deviations for the variables (personal dispositions, semantic aspects)

\begin{tabular}{|c|c|c|}
\hline Scale & M & $S D$ \\
\hline \multicolumn{3}{|c|}{$\begin{array}{l}\text { Leary's Interpersonal Behavior Circle Personal } \\
\text { Inventory }\end{array}$} \\
\hline 1. Managerial - autocratic (I) & 7.36 & 3.77 \\
\hline 2. Competitive - narcissistic (II) & 6.05 & 3.24 \\
\hline 3. Aggressive - sadistic (III) & 6.31 & 3.13 \\
\hline 4. Rebellious - distrustful (IV) & 5.84 & 2.98 \\
\hline 5. Self-effacing - masochistic (V) & 5.32 & 3.21 \\
\hline 6. Docile - dependent (VI) & 4.93 & 2.99 \\
\hline $\begin{array}{l}\text { 7. Cooperative - } \\
\text { over-conventional (VII) }\end{array}$ & 6.50 & 3.01 \\
\hline $\begin{array}{l}\text { 8. Responsible - hyper-normal } \\
\text { (VIII) }\end{array}$ & 7.19 & 3.70 \\
\hline \multicolumn{3}{|l|}{ Semantic differential } \\
\hline 9. Easy - heavy $(\mathrm{EH}+)$ & 4.68 & 1.75 \\
\hline 10. Good - evil (GE+) & 5.78 & 1.28 \\
\hline 11. Clean - dirty $(C D+)$ & 6.08 & 1.09 \\
\hline 12. Hot - cold $(\mathrm{HC}+)$ & 5.13 & 1.50 \\
\hline 13. Hard - soft (HS-) & 4.20 & 1.88 \\
\hline 14. Old - young (OY-) & 5.90 & 1.55 \\
\hline 15. Stupid - clever (SC-) & 5.55 & 1.48 \\
\hline 16. Loud - quiet (LQ-) & 3.31 & 1.83 \\
\hline 17. Fast - slow $(\mathrm{FS}+)$ & 5.21 & 1.61 \\
\hline 18. Satiated - hungry $(\mathrm{SH}+)$ & 4.77 & 1.74 \\
\hline 19. Repulsive - pleasant (RP-) & 5.34 & 1.47 \\
\hline 20. Active - passive $(\mathrm{AP}+)$ & 5.71 & 1.53 \\
\hline 21. Bitter - sweet (BS-) & 5.19 & 1.44 \\
\hline 22. Brave - cowardly (BC-) & 5.65 & 1.33 \\
\hline 23. Strong - weak (SW+) & 5.55 & 1.36 \\
\hline 24. Miserable - happy (MH-) & 5.66 & 1.60 \\
\hline
\end{tabular}

Circle Personal Inventory (Leary, 2004). The questionnaire offers 128 characteristics. This inventory was adapted into Russian by Sobchyk (2005).

The semantic differential. The second group of variables was connected with the perception of help. The characteristics were rated according to the fact that they represented positive or negative characteristics from the beginning, so these characteristics were evaluated in direct $(+)$ or reverse $(-)$ order: easy heavy $(\mathrm{EH}+)$, good - evil (GE+), clean - dirty $(\mathrm{CD}+)$, hot - cold $(\mathrm{HC}+)$, hard - soft (HS-), old - young (OY-), stupid - clever (SC-), loud - quiet (LQ-), fast - slow $(\mathrm{FS}+)$, satiated - hungry $(\mathrm{SH}+)$, repulsive pleasant $(\mathrm{RP}-)$, active - passive $(\mathrm{AP}+)$, bitter - sweet (BS-), brave - cowardly (BC-), strong - weak (SW+), miserable - happy (MH-). These variables were measured by the semantic differential (Artiemieva, 1999).

In the semantic differential, the following instruction was given to our respondents: "Please evaluate your notions about help to the other. You have a list of grouped adjectives that are connected to the qualitatively polar characteristics of the evaluated notion. Please underline the number from the 3210123 range that to your mind most accurately corresponds to the level of the expressiveness of the characters, with the condition that 0 means that the characteristics are not expressed, 1 - low expressed, 2 - moderately expressed, 3 - highly expressed. Please don't miss the pairs of words and choose from each pair. Thank you for your cooperation!" (Artiemieva, 1999).

Both techniques were proved to be valid, reliable and accurate (Leary, 2004; Artiemieva, 1999). The correlations of Leary's Interpersonal Behavior Circle Personal Inventory with other psychodiagnostic techniques is .78 (Sobchyk, 2005), and this proves the reliability of the inventory. The accuracy of the semantic differential was proved on a sample of 1000 people: the quantity of full matches (18 of 25) is significantly different from random ( $\chi^{2}$ 95\% reliability) (Artiemieva, 1999).

\section{PROCEDURE}

The participants answered the questions of Leary's Interpersonal Behavior Circle Personal Inventory, adapted into Russian by Sobchyk (2005), and ranked the qualities of the semantic differential for the words "help to the other". Thus aim of the research was to study interconnections of personal dispositions to the perception of the help to the other. Afterwards, correlational analysis using Spearman's correlation and SPSS 23.0 was performed.

\section{RESULTS}

The most significant correlations of the managerial - autocratic (I) disposition are with the seman- 
Maria M. Nakonechna, Eugene Stepura, Mykola Papucha, Vladimir Koshel, Alexander Segal, Anna Fedorova

Table 2

Spearman's correlations between the personal dispositions and semantic aspects

\begin{tabular}{lcccccccc}
\hline & $\mathrm{I}$ & $\mathrm{II}$ & $\mathrm{III}$ & $\mathrm{IV}$ & $\mathrm{V}$ & $\mathrm{VI}$ & $\mathrm{VII}$ & VIII \\
\hline $\mathrm{EH}+$ & -.06 & -.06 & -.08 & -.05 & .11 & .09 & .12 & $.25^{* *}$ \\
$\mathrm{GE}+$ & -.07 & $-.18^{*}$ & $-.19^{*}$ & -.11 & .12 & .06 & .13 & $.28^{* *}$ \\
$\mathrm{CD}+$ & .13 & $.15^{*}$ & .04 & -.06 & -.06 & .03 & $.16^{*}$ & $.17^{*}$ \\
$\mathrm{HC}+$ & $.23^{* *}$ & $.17^{*}$ & $.16^{*}$ & .03 & $-.22^{* *}$ & -.07 & .03 & -.02 \\
$\mathrm{HS}-$ & -.07 & -.08 & $-.16^{*}$ & -.01 & $.15^{*}$ & $.15^{*}$ & .10 & $.24^{* *}$ \\
$\mathrm{OY}-$ & .11 & .13 & .05 & -.002 & $-.16^{*}$ & -.12 & -.02 & -.06 \\
$\mathrm{SC}-$ & $.15^{*}$ & .07 & -.06 & -.08 & -.08 & .01 & .07 & .11 \\
$\mathrm{LQ}-$ & $-.32^{* *}$ & $-.24^{* *}$ & $-.27^{* *}$ & -.08 & $.18^{*}$ & -.07 & $-.16^{*}$ & -.03 \\
$\mathrm{FS}+$ & $.28^{* *}$ & $.20^{* *}$ & .06 & -.003 & $-.21^{* *}$ & -.03 & .10 & -.001 \\
$\mathrm{SH}+$ & .03 & -.08 & -.13 & $-.20^{* *}$ & $-.15^{*}$ & -.05 & -.05 & .03 \\
$\mathrm{RP}-$ & -.01 & -.13 & -.13 & $-.18^{*}$ & -.06 & -.14 & -.07 & .02 \\
$\mathrm{AP}+$ & $.38^{* *}$ & $.23^{* *}$ & .09 & -.01 & -.01 & .08 & .12 & .08 \\
$\mathrm{BS}-$ & .13 & .05 & .04 & -.002 & -.05 & .02 & .11 & .13 \\
$\mathrm{BC}-$ & $.31^{* *}$ & $.27^{* *}$ & .13 & .03 & $-.27^{* *}$ & -.03 & .08 & .05 \\
$\mathrm{SW}+$ & $.22^{* *}$ & $.20^{* *}$ & .07 & .07 & $-.19^{* *}$ & -.05 & .05 & .02 \\
$\mathrm{MH}-$ & $.14^{*}$ & .08 & .02 & -.11 & -.03 & -.04 & .05 & .19 \\
\hline $\mathrm{N}+\mathrm{Th}$ & 2.03 &
\end{tabular}

Note. The semantic aspects are as follows: easy - heavy $(\mathrm{EH}+)$, good - evil $(\mathrm{GE}+)$, clean - dirty $(\mathrm{CD}+)$, hot - cold $(\mathrm{HC}+)$, hard - soft (HS-), old - young (OY-), stupid - clever (SC-), loud - quiet (LQ-), fast - slow (FS+), satiated - hungry (SH+), repulsive - pleasant (RP-), active - passive (AP+), bitter - sweet (BS-), brave - coward (BC-), strong - weak (SW+), miserable - happy (MH-). The personal dispositions are as follows: managerial - autocratic (I), competitive - narcissistic (II), aggressive - sadistic (III), rebellious - distrustful (IV), self-effacing - masochistic (V), docile - dependent (VI), cooperative - over-conventional (VII) and responsible - hyper-normal (VIII). ${ }^{*} p<.05,{ }^{* *} p<.01$.

tic perceptions of hot - cold, $\mathrm{HC}+(r=.23, p<.01)$, fast - slow, FS $+(r=.28, p<.01)$, active - passive, $\mathrm{AP}+(r=.38, p<.01)$, brave - cowardly, $\mathrm{BC}-(r=.31$, $p<.01)$ and strong - weak, SW+ $(r=.22, p<.01)$. The managerial - autocratic disposition negatively correlates with loud - quiet, LQ- $(r=-.32, p<.01)$. It means that the better leader the person is, the better organizer he/she is, the more self-confident he/she is, the more tendencies to perceive help as hot, fast, active, cowardly, strong and loud he/she will have. It can be interpreted thus. Such people will engage in helping others quickly, but they will act prosocially for different goals - for loud results of being popular, dominant, or powerful. It will also be characteristic for such people to think that weak people and cowards need help.

The competitive - narcissistic (II) disposition positively correlates with the semantic perceptions fast - slow, FS $+(r=.20, p<.01)$, active - passive, $\mathrm{AP}+(r=.23, p<.01)$, brave - cowardly, $\mathrm{BC}-(r=.27$, $p<.01)$ and strong - weak, SW+ $(r=.20, p<.01)$ and negatively correlates with loud - quiet, LQ $-(r=-.24$, $p<.01)$. It is fascinating that four of five significant correlations are the same as with the managerial autocratic (I) disposition. It means that the perceptions of help among people with such dispositions are similar. The difference is that the help is perceived as loud. So people who are confident, independent, and competitive tend to perceive help as a means of self-advertisement. These people help so that their actions become known to others. For individuals with the competitive - narcissistic disposition, it is essential to be better than others, in particular when this means helping others (for instance, helping more often or more significantly).

The aggressive-sadistic (III) disposition negatively correlates with the semantic perceptions of loud quiet, LQ- $(r=-.27, p<.01)$. It means that for sincere, spontaneous, straightforward people, the importance of the other's awareness about their help is very high. It is deeply connected to their behavioral style. It does not mean that these people are demonstrative in an unhealthy way. They do not need others' attention. The loudness of help is connected to inner peculiarities of these people, who are used to dynamic behavior. 
The only correlation significant at the level $p<.01$ for the rebellious - distrustful (IV) disposition is with the semantic perception of help as satiated - hungry, $\mathrm{SH}+(r=-.20)$. These people tend to help only in situations when help is explicitly needed. It is connected to the skepticism and distrustfulness of these people. The central tendency here is that help can be provided when a person clearly understands that the other truly needs help. Strong arguments should be submitted to motivate such people to help.

The self-effacing - masochistic (V) disposition has the following significant correlations: hot - cold, $\mathrm{HC}+(r=-.22, p<.01)$, fast - slow, FS $+(r=-.21$, $p<.01)$, brave - cowardly, BC- $(r=-.27, p<.01)$, strong - weak, SW+ $(r=-.19, p<.01)$. These people are not able to be active prosocially and to help others because of their character. They feel weak in helping others, they are afraid to make it worse because of their help, and thus they have hesitancy and distance from others.

The docile - dependent (VI) disposition has only one significant correlation, with hard - soft, HS$(r=.15, p<.05)$. People with this disposition perceive help as soft. It has two possible accents at the same time: (1) softness as tenderness, the tendency to be useful to people, and (2) softness as weakness, the personal loss of desire to help, the lack of a core which would enable the person to help others. At the same time this disposition has the fewest correlations, which could be interpreted as meaning that these people do not tend to help, and charitable deeds are not relevant to them.

The cooperative - over-conventional (VII) disposition correlates with clean - dirty, $\mathrm{CD}+(r=.16$, $p<.05)$, and loud - quiet, LQ- $(r=.16, p<.05)$. In other words, the more friendly and willing to cooperate the person is, the more likely he/she would perceive help as "clean" and "quiet". It means that the person does not tend to demonstrative prosocial behavior. The person prefers to be good to others in a quiet way, without loud publicity about the good acts he/she did.

The responsible - hyper-normal disposition (VIII) in Leary's inventory correlates with the semantic perceptions of easy - heavy, EH+ $(r=.25, p<.01)$, good - evil, GE $+(r=.28, p<.01)$ and hard - soft, HS- $(r=.24, p<.01)$. It means that the more hypersocial, altruistic, ready to help others the individual is, the more evident is the tendency of the individual to perceive help as "easy", "good" and "soft". Help is viewed positively. People with the responsible - hyper-normal disposition are hard in their intentions to help; the very act of help is not supposed to be hard and difficult. These people are clear in their intentions and do not use the help to others for egoistic purposes. Help (for these people) is first of all the explication of kindness as a personal trait.

\section{DISCUSSION}

Our investigation contributed to reflecting on the balance of the situational and constant factors in helping behavior. On the one hand, perceiving help can be situational and was studied with situational psychodiagnostic techniques, although some people can consistently recognize help to others in a particular manner. On the other hand, interpersonal dispositions are somewhat constant, but this consistency has its limitations. Generally, the correlations identified between the variables in our research give an insight into the complex interrelationships of regular and situational factors in the prosocial activity problem.

Our research corresponds to Vygotsky's cultural-historical theory (Vygotsky, 1978), in particular to the ideas about the development of notions and interfunctional psychological systems. The perception of helping the other changes according to the change of notions about help. So the results of our study are a one-time cut-out in perceiving help. But the fact that it correlates with the interpersonal relational style shows that there is a broader psychological system in which perception of help and interpersonal relational styles change and develop. Thus the interconnections of perceiving help and different relational styles can be explained thus: they all are in a process of development, and changes in notions and perceptions about help induce the changes in relational styles, and vice-versa.

The correlations of managerial - autocratic (I) disposition with different aspects of semantic differential may suggest that people with this disposition think of themselves as strong and able to help, but that makes the others weak. It is important for people with the managerial - autocratic disposition to influence society, and helping others can be one of the means of it. These people are usually selfconfident, can be good organizers, and thus helping others is a means to reinforce their social status. So according to Vygotsky's theory (Vygotsky, 1978), the characteristics of managerial - autocratic (I) disposition form an interfunctional psychological system with the peculiarities of perceiving help. It shows the nature and direction of personal development in the domain of prosocial tendencies. The interpsychological processes presented in managerial - autocratic (I) disposition are deeply interconnected with intrapsychological processes of perceiving help. In the research on cyberbullying among adolescent bystanders (Barlinska et al., 2018) it is important to perceive the situation as cyberbullying and situations where prosocial interventions are needed. The investigation of the effects of being watched on prosocial tendencies (Cañigueral \& Hamilton, 2019) is also intertwined with perceiving help. So different aspects of intrapsychological processes such as perceiving help 
can be connected to interpsychological processes such as relational styles.

Age (Foulkes et al., 2018) and cultural (Hepach \& Herrmann, 2019) peculiarities are important for prosocial activity, being strongly connected to semantic, personal and communicational aspects of help. The research results show that each interpersonal disposition has a specific pattern of correlations with the way people perceive the concept of helping the other. The most interesting is the deep connection of the motives to help others with the managerial - autocratic (I), the competitive - narcissistic (II), and the responsible - hyper-normal (VIII) dispositions.

The results need further clarification, for these are the first steps in exploring the relations between interpersonal dispositions and semantic peculiarities of the perception of the "helping the other" concept. The present study not only answered our research questions but also revealed the field of future interest in the subject, which is connected with personal dispositions that influence prosocial behavior.

Practical implications for our research are connected with the possibilities of use of the obtained results in the sphere of providing psychological help for those who need it. Knowing the interconnections of semantic, communicational and personal aspects of help, a practicing psychologist can be more effective in counseling and psychodiagnostic interactions with clients. The results of the research can be used in teaching various university courses in psychology, in particular social psychology.

\section{NOVELTY AND RELEVANCE}

What is already known about the topic? Psychological aspects of helping have been studied in various contexts. Help has been explained through morality, motivation, cultural values etc. Different age periods were studied in investigations of helping behavior. Effects of an audience (Cañigueral \& Hamilton, 2019), prosocial cyberbystander behavior (Barlinska et al., 2018), interconnections between moral disengagement and active defending versus passive bystanding during bullying situations (Doramajian \& Bukowski, 2015), the influence of age and culture on prosocial activity (Foulkes et al., 2018; Hepach \& Herrmann, 2019) and other aspects of prosocial engagement have been studied empirically.

What does this paper add? The connections of how a person perceives help to others and his/her personal traits are studied in this article. For instance, it is shown that the better leader the person is, the better organizer he/she is (personal aspects), the more tendencies to act prosocially for the results of being popular, dominant, or powerful he/she will have (semantic and communicative aspects).

\section{CONCLUSIONS}

Our research contributed to understanding the interconnectedness of semantic aspects of perceiving help with personal traits. It does not only mean such a narrow perspective as the relations between perceiving help and Leary's dispositions, but also tends to explain the psychological nature of the personality in a situation of help. The main theoretical framework of our investigation is Vygotsky's cultural-historical theory (Vygotsky, 1978; Dafermos, 2018; Langford, 2005). Our research considers mainly the connection of semantic aspects of perceiving prosocial (helping) actions with the personal tendencies to act in a certain way in this situation.

Each disposition from Leary's questionnaire had at least one significant correlation with the way Ukrainian adolescents perceive help. The semantic aspects of perceiving help were investigated with the help of ranking the qualities of the semantic differential for the words "helping the other". The correlations identified contribute to the psychological analysis of the detailed characteristics of perceiving help to personal dispositions. In particular, correlations of semantic aspects of help with the managerial - autocratic (I), the competitive - narcissistic (II), and the responsible - hyper-normal (VIII) dispositions were found. Summing up, it should be noted that personal, communicational and semantic aspects of help are interconnected and their further research can bring rich insights.

The areas of future research are connected to studying help as a real-life situation and more detailed investigation of help in the context of the zone of proximal development (Vygotsky, 1978). The semantic aspects that are changing and developing under the influence of real-life help should be studied in detail, contributing to the idea of the developing ideas and notions.

\section{RefERENCES}

Armenta, B. E., Knight, G. P., Carlo, G., \& Jacobson, R. P. (2010). The relation between ethnic group attachment and prosocial tendencies: The mediating role of cultural values. European Journal of Social Psychology, 41, 107-115. https://doi. org/10.1002/ejsp.742

Artiemieva, E. J. (1999). Osnovy psichologii subjektivnoj semantiki [The fundamentals of subjective semantics psychology]. Nauka, Smysl.

Barlinska, J., Szuster, A., \& Winiewski, M. (2018). Cyberbullying among adolescent bystanders: Role of affective versus cognitive empathy in increasing prosocial cyberbystander behavior. Frontiers in Psychology, 9, 799. https://doi.org/10.3389/fpsyg. 2018.00799 
Cañigueral, R., \& Hamilton, A. F. C. (2019). Being watched: Effects of an audience on eye gaze and prosocial behavior. Acta Psychologica, 195, 50-63. https://doi.org/10.1016/j.actpsy.2019.02.002

Dafermos, M. (2018). Rethinking cultural-historical theory: a dialectical perspective to Vygotsky. Springer Nature.

Deci, E., \& Ryan, R. (1985). The general causality orientations scale: Self-determination in personality. Journal of Research in Personality, 19, 109-134. https://doi.org/10.1016/0092-6566(85)90023-6

Ding, W., Shao, Y., Sun, B., Xie, R., Li, W., \& Wang, X. (2018). How can prosocial behavior be motivated? The different roles of moral judgment, moral elevation, and moral identity among the young Chinese. Frontiers in Psychology, 9, 814. https:// doi.org/10.3389/fpsyg.2018.00814

Doramajian, C., \& Bukowski, W. M. (2015). A longitudinal study of the associations between moral disengagement and active defending versus passive bystanding during bullying situations. Merrill-Palmer Quarterly, 61, 144-172. https://doi. org/10.13110/merrpalmquar1982.61.1.0144

Fonseca, B. R., Cavalcante, L. I. C., Kärtner, J., \& Köster, M. (2018). Maternal socialization goals and the spontaneous prosocial behavior of children in rural contexts. Psicologia: Reflexao e Critica, 31, 27. https://doi.org/10.1186/s41155-018-0108-x

Foulkes, L., Leung, J. T., Fuhrmann, D., Knoll, L. J., \& Blakemore, S. J. (2018). Age differences in the prosocial influence effect. Developmental Science, 21, e12666. https://doi.org/10.1111/desc.12666

Freitas, M., Santos, A. J., Ribeiro, O., Daniel, J. R., \& Rubin, K. H. (2019). Prosocial behavior and friendship quality as moderators of the association between anxious withdrawal and peer experiences in Portuguese young adolescents. Frontiers in Psychology, 9, 2783. https://doi.org/10.3389/ fpsyg.2018.02783

Hammond, S. I., \& Brownell, C. A. (2018). Happily unhelpful: Infants' everyday helping and its connections to early prosocial development. Frontiers in Psychology, 9, 1770. https://doi.org/10.3389/ fpsyg.2018.01770

He, J., Koot, H. M., Buil, J. M., \& van Lier, P. A. C. (2018). Impact of low social preference on the development of depressive and aggressive symptoms: Buffering by children's prosocial behavior. Journal of Abnormal Child Psychology, 46, 14971507. https://doi.org/10.1007/s10802-017-0382-6

Hepach, R., \& Herrmann, E. (2019). The development of prosocial attention across two cultures. Frontiers in Psychology, 10, 138. https://doi.org/10.3389/ fpsyg.2019.00138

Johnson, M., \& Krettenauer, T. (2011). Moral self and moral emotion expectancies as predictors of anti- and prosocial behavior in adolescence: a case for mediation? European Journal of De- velopmental Psychology, 8, 228-243. https://doi. org/10.1080/17405621003619945

Kacmar, K. M., Carlson, D. S., \& Harris, K. J. (2013). Interactive effect of leader's influence tactics and ethical leadership on work effort and helping behavior. The Journal of Social Psychology, 153, 577597. https://doi.org/10.1080/00224545.2013.798248

Kleemans, M., Schlindwein, L. F., \& Dohmen, R. (2017). Preadolescents' emotional and prosocial responses to negative TV news: Investigating the beneficial effects of constructive reporting and peer discussion. Journal of Youth and Adolescence, 46, 20602072. https://doi.org/10.1007/s10964-017-0675-7

Knafo, A., \& Plomin, R. (2006). Prosocial behavior from early to middle childhood: Genetic and environmental influences on stability and change. Developmental Psychology, 42, 771-786. https:// doi.org/10.1037/0012-1649.42.5.771

Kraft-Todd, G. T., \& Rand, D. G. (2019). Rare and costly prosocial behaviors are perceived as heroic. Frontiers in Psychology, 10, 234. https://doi.org/10.3389/ fpsyg.2019.00234

Langford, P. E. (2005). Vygotsky's developmental and educational psychology. Psychology Press, Taylor and Francis Group.

Leary, T. (2004). Interpersonal diagnosis of personality. Resource Publications.

Malti, T., Ongley, S. F., Peplak, J., Chaparro, M. P., Buchmann M., Zuffianò, A., \& Cui, L. (2016). Children's sympathy, guilt, and moral reasoning in helping, cooperation, and sharing: a 6-year longitudinal study. Child Development, 87, 1783-1795. https://doi.org/10.1111/cdev.12632

Marques, S. C., Pais-Ribeiro, J. L., \& Lopez S. J. (2011). The role of positive psychology constructs in predicting mental health and academic achievement in children and adolescents: a two-year longitudinal study. Journal of Happiness Studies, 12, 10491062. https://doi.org/10.1007/s10902-010-9244-4

Martí-Vilar, M., Corell-García, L., \& Merino-Soto, C. (2019). A systematic review of prosocial behavior measures. Revista de Psicología, 37, 349-377 https:// doi.org/10.18800/psico.201901.012

Newton, E. K., Thompson, R. A., \& Goodman, M. (2016). Individual differences in toddlers' prosociality: Experiences in early relationships explain variability in prosocial behavior. Child Development, 87 , 1715-1726. https://doi.org/10.1111/cdev. 12631

Oerlemans, A., Rommelse, N., Buitelaar, J., \& Hartman, C. (2018). Examining the intertwined development of prosocial skills and ASD symptoms in adolescence. European Child \& Adolescent Psychiatry, 27, 1033-1046. https://doi.org/10.1007/ s00787-018-1114-3

Pakaslahti, L., Karjalainen, A., \& Keltikangas-Järvinen, L. (2002). Relationships between adolescent prosocial problem-solving strategies, prosocial behavior, and social acceptance. International 
Journal of Behavioral Development, 26, 137-144. https://doi.org/10.1080/01650250042000681

Park, Y. N., Hyun, H., \& Jhang, J. H. (2019). Do emotional laborers help the needy more or less? The mediating role of sympathy in the effect of emotional dissonance on prosocial behavior. Frontiers in Psychology, 10, 118. https://doi.org/10.3389/ fpsyg.2019.00118

Penner, L. A., Dovidio, J. F., Piliavin, J. A., \& Schroeder, D. A. (2005). Prosocial behavior: Multilevel perspectives. Annual Review of Psychology, 56, 365-392. https://doi.org/10.1146/annurev.psych. 56.091103.070141

Recchia, H. R., Wainryb, C., Bourne, S., \& Pasupathi, M. (2015). Children's and adolescents' accounts of helping and hurting others: Lessons about the development of moral agency. Child Development, 86, 864-876. https://doi.org/10.1111/cdev.12349

Reis, H., Sheldon, K., Gable, S., Roscoe, J., \& Ryan, R. (2000). Daily well-being: The role of autonomy, competence, and relatedness. Personality and Social Psychology Bulletin, 26, 419-435. https://doi. org/10.1177/0146167200266002

Sobchyk, L. N. (2005). Psichologia individualnosti. Teoria i praktika psichodiagnostiki [The individuality psychology. Theory and practice of psychodiagnostics]. Rech Publishing House.

Tian, L., Zhang, X., \& Huebner, E. S. (2018). The effects of satisfaction of basic psychological needs at school on children's prosocial behavior and antisocial behavior: The mediating role of school satisfaction. Frontiers in Psychology, 9, 548. https:// doi.org/10.3389/fpsyg.2018.00548

Tsang, J. A. (2006). Gratitude and prosocial behavior: an experimental test of gratitude. Cognition and Emotion, 20, 138-148. https://doi.org/10. 1080/02699930500172341

Van der Graaff, J., Carlo, G., Crocetti, E., Koot, H. M., \& Branje, S. (2018). Prosocial behavior in adolescence: Gender differences in development and links with empathy. Journal of Youth and Adolescence, 47, 1086-1099. https://doi.org/10.1007/ s10964-017-0786-1

van Doorn, J., Zeelenberg, M., Breugelmans, S. M., Berger, S., \& Okimoto, T. G. (2018). Prosocial consequences of third-party anger. Theory and Decision, 84, 585-599. https://doi.org/10.1007/s11238017-9652-6

Vygotsky, L. S. (1978). Mind in society. Harvard University Press.

Wang, X., Han, J., Li, F., \& Cao, B. (2018). Both rewards and moral praise can increase the prosocial decisions: Revealed in a modified ultimatum game task. Frontiers in Psychology, 9, 1865. https:// doi.org/10.3389/fpsyg.2018.01865

Weinstein, N., DeHaan, C. R., \& Ryan, R. M. (2010). Attributing autonomous versus introjected motivation to helpers and the recipient experience:
Effects on gratitude, attitudes, and well-being. Motivation and Emotion, 34, 418-431. https://doi. org/10.1007/s11031-010-9183-8

Zhang, J., \& Zhao, L. (2017). Interactive effects of appeal type and social distance on helping intention. Social Behavior and Personality, 45, 785-794. https://doi.org/10.2224/sbp.6070 